\title{
Role of liver support systems in the management of post hepatectomy liver failure: A systematic review of the literature
}

\author{
Kamil Pufal ${ }^{1,2}$, Alexander Lawson ${ }^{1,2}$, James Hodson ${ }^{3}$, Mansoor Bangash ${ }^{2,4}$, \\ Jaimin Patel ${ }^{2,4}$, Chris Weston ${ }^{5}$, Thomas van Gulik ${ }^{6}$, and Bobby VM Dasari ${ }^{1,2}$ \\ ${ }^{1}$ Department of HPB and Liver Transplantation, Queen Elizabeth Hospital, \\ ${ }^{2}$ University of Birmingham, ${ }^{3}$ Institute of Translational Medicine, Queen Elizabeth Hospital Birmingham, \\ ${ }^{4}$ Department of Anaesthesia and Critical Care, Queen Elizabeth Hospital, \\ ${ }^{5}$ Centre for Liver \& Gastrointestinal Research, Institute of Immunology \& Immunotherapy, \\ College of Medical and Dental Sciences, University of Birmingham, Birmingham, UK, \\ ${ }^{6}$ Department of Surgery, University Medical Centres (Location Amsterdam Medical Centre), \\ University of Amsterdam, Amsterdam, The Netherlands
}

\begin{abstract}
Backgrounds/Aims: Post-hepatectomy liver failure (PHLF) is a serious complication following liver resection, with limited treatment options, and is associated with high mortality. There is a need to evaluate the role of systems that support the function of the liver after PHLF. Aims: The aim of this study was to review the literature and summarize the role of liver support systems (LSS) in the management of PHLF. Publications of interest were identified using systematically designed searches. Following screening, data from the relevant publications was extracted, and pooled where possible. Findings: Systematic review identified nine studies, which used either Plasma Exchange (PE) or Molecular Adsorbent Recirculating System (MARS) as LSS after PHLF. Across all studies, the pooled 90-day mortality rate was $38 \%(95 \%$ CI: 9-70\%). However, there was substantial heterogeneity, likely since studies used a variety of definitions for PHLF, and had different selection criteria for patient eligibility for LSS treatment. Conclusions: The current evidence is insufficient to recommend LSS for the routine management of severe PHLF, with the current literature consisting of only a limited number of studies. There is a definite need for larger, multicenter, prospective studies, evaluating the conventional and newer modalities of support systems, with a view to improve the outcomes in this group of patients. (Ann Hepatobiliary Pancreat Surg 2021;25:171-178)
\end{abstract}

Key Words: Post hepatectomy liver failure; Liver resection; MARS; Plasma exchange system

\section{INTRODUCTION}

The reported incidence of post-hepatectomy liver failure (PHLF) is variable, ranging from 0.7 to $35 \% .^{1-5}$ The overall 90-day mortality after hepatectomy remains at $3-5 \%,{ }^{2,6-8}$ with PHLF being one of the major causes of these mortalities. Whereas PHLF Grade A requires no changes in post-operative management, PHLF Grade B and $\mathrm{C}$ require significant adjustments in management and intensive care therapy, respectively. PHLF can cause multi-system organ failure, and can result in the development of hepatic encephalopathy or renal failure.
Treatment of high grade PHLF in the immediate postoperative period includes control and treatment of sepsis, nutritional supplementation, and replacement of blood components such as albumin, fibrinogen, and plasma. Additionally, multi-organ support with hemodialysis to control metabolic acidosis and prevent fluid overload, the use of vasopressors to maintain an adequate perfusion pressure in the face of vasoplegia, and ventilatory support in cases of respiratory failure or failure to protect the airway during encephalopathy are variably required, depending on the severity of PHLF. The mortality rates associated with the different grades of PHLF range from $0 \%$ at Grade A

Received: December 31, 2020; Revised: February 4, 2021; Accepted: February 5, 2021

Corresponding author: Bobby VM Dasari

Department of HPB and Liver Transplantation, Queen Elizabeth Hospital, Edgbaston, Birmingham, B15 2TH, UK Tel: +44-1213714638, Fax: +44-1214141833, E-mail: bobby.dasari@yahoo.com

Copyright (C) 2021 by The Korean Association of Hepato-Biliary-Pancreatic Surgery

This is an Open Access article distributed under the terms of the Creative Commons Attribution Non-Commercial License (http://creativecommons.org/ censes/by-nc/4.0) which permits unrestricted non-commercial use, distribution, and reproduction in any medium, provided the original work is properly cited. Annals of Hepato-Biliary-Pancreatic Surgery • pISSN: 2508-5778 - elSSN: 2508-5859 
to $50 \%$ at Grade C. ${ }^{1,5,8}$ Liver support systems (LSS) are extracorporeal systems that can act as bridging therapies while hepatic recovery is awaited. They are designed to replace some major functions of hepatocytes in an ex vivo environment, thus permitting time for hepatic recovery. ${ }^{9}$ Systems may be artificial, bio-artificial, or hybrid. Artificial systems currently can only replace detoxification functions of the liver, while bio-artificial systems are designed to also support biosynthesis and a degree of physiological regulation.

One of the most popular and common LSS used in the clinical setting is the Molecular Adsorbent Recirculating System (MARS). It allows the removal of hepatotoxins, such as bilirubin, without affecting secretory functions. ${ }^{10,11}$ The function of MARS is based on the concepts of dialysis, filtration, and adsorption, and constitutes three main components: the blood circuit, the albumin circuit, and the low-flux dialysis circuit. ${ }^{12,13}$ Another common LSS is plasma exchange (PE), which is a form of extracorporeal liver support, and is used to either extract and detoxify the patient's plasma, or replace it with fresh-frozen plasma. PE removes large-molecular-weight substances from the plasma. It is usually carried out using an automated blood cell separator, to ensure fluid balance and maintain a normal plasma volume. Typically, $30-40 \mathrm{ml} / \mathrm{kg}$ of plasma (11.5 plasma volumes) are removed at each cycle through a femoral or jugular line, and replaced with isotonic 4.5 or $5.0 \%$ human albumin solution. A one plasma volume exchange removes approximately $66 \%$ of an intravascular constituent, increasing to approximately $85 \%$ for a two plasma volume exchange. ${ }^{14,15}$

The aim of this study was to perform a systematic review of the literature, to assess the role of LSS in the management of PHLF.

\section{METHODS}

Systematic searches through Embase and MEDLINE ${ }^{\circledR}$ databases using the previously specified search strategy and terms were undertaken. Following the searches, the abstracts were extracted from Embase and MEDLINE ${ }^{\circledR}$, and pooled into EndNote.

\section{Inclusion and Exclusion Criteria for the review}

Randomised controlled trials and observational studies reporting the mortality rates of patients who developed PHLF and were managed using any LSS were included. All studies published between January 1985 and March 2020 were included. Studies assessing the use of LSS outside of the context of PHLF (i.e. medical causes of liver failure and post-liver transplantation) were excluded. Case reports, animal studies, and non-English language studies were also excluded.

Studies were identified from the Embase and MEDLINE ${ }^{\circledR}$ online databases. Embase was accessed via Ovid, and included titles from January 1974 to March 2020. MEDLINE ${ }^{\circledR}$ was also accessed via Ovid and the database included titles from 1946 to March 2020. In order to identify eligible publications, screening of titles along with their abstracts against the inclusion criteria was performed independently by two reviewers (KP and AL). Any failure to reach consensus regarding study eligibility was resolved by discussion with a third senior reviewer (BD). The specific search terms used alongside the order of searches can be found in Supplementary Table 1.

The review protocol followed the Patient, Intervention, Comparison, Outcome (PICO) framework. ${ }^{16}$ Patients who underwent a hepatectomy procedure and subsequently developed PHLF formed the population of interest. The use of a LSS following the development of PHLF was the intervention of interest. The primary outcome was the 90 -day mortality rate following support system therapy.

\section{PHLF Definition}

All patients under consideration for LSS had been diagnosed with PHLF. However, no limits on the definition of PHLF used, or the eligibility criteria for LSS treatment were applied as part of the literature review.

\section{Quality Assessment of Studies}

Full text articles were assessed for risk of bias and quality. The Risk of Bias in Non-Randomized Studies Of Interventions (ROBINS-I) tool was utilized. The overall judgment of the risk of bias was recorded using a spreadsheet in Excel (Microsoft ${ }^{\circledR}$, Redmond, Washington, United States) along with additional notes and comments (Supplementary Table 2).

\section{Statistical Methods}

Due to the small sample sizes, the primary analysis in- 
cluded all studies, regardless the type of LSS used, with subgroup analyses also being performed to assess these separately. In order to pool the 90-day mortality rates across studies, the data were first transformed using the approach described by JJ Miller. ${ }^{17}$ The resulting values were then entered into a random-effects meta-analysis model with inverse-variance weighting. The pooled mortality rates were then reported along with the associated $95 \%$ confidence intervals (CIs) and heterogeneity $\left(\mathrm{I}^{2}\right)$ statistics.

\section{RESULTS}

\section{Search Criteria}

A flow diagram for the systematic searches and reasons for exclusions is shown in Fig. 1. Data from nine studies were included in the review, of which five reported the use of MARS and four reported the use of PE; ${ }^{18-26}$ no other LSS were reported.

\section{Study characteristics}

No randomized control trials were found. The available

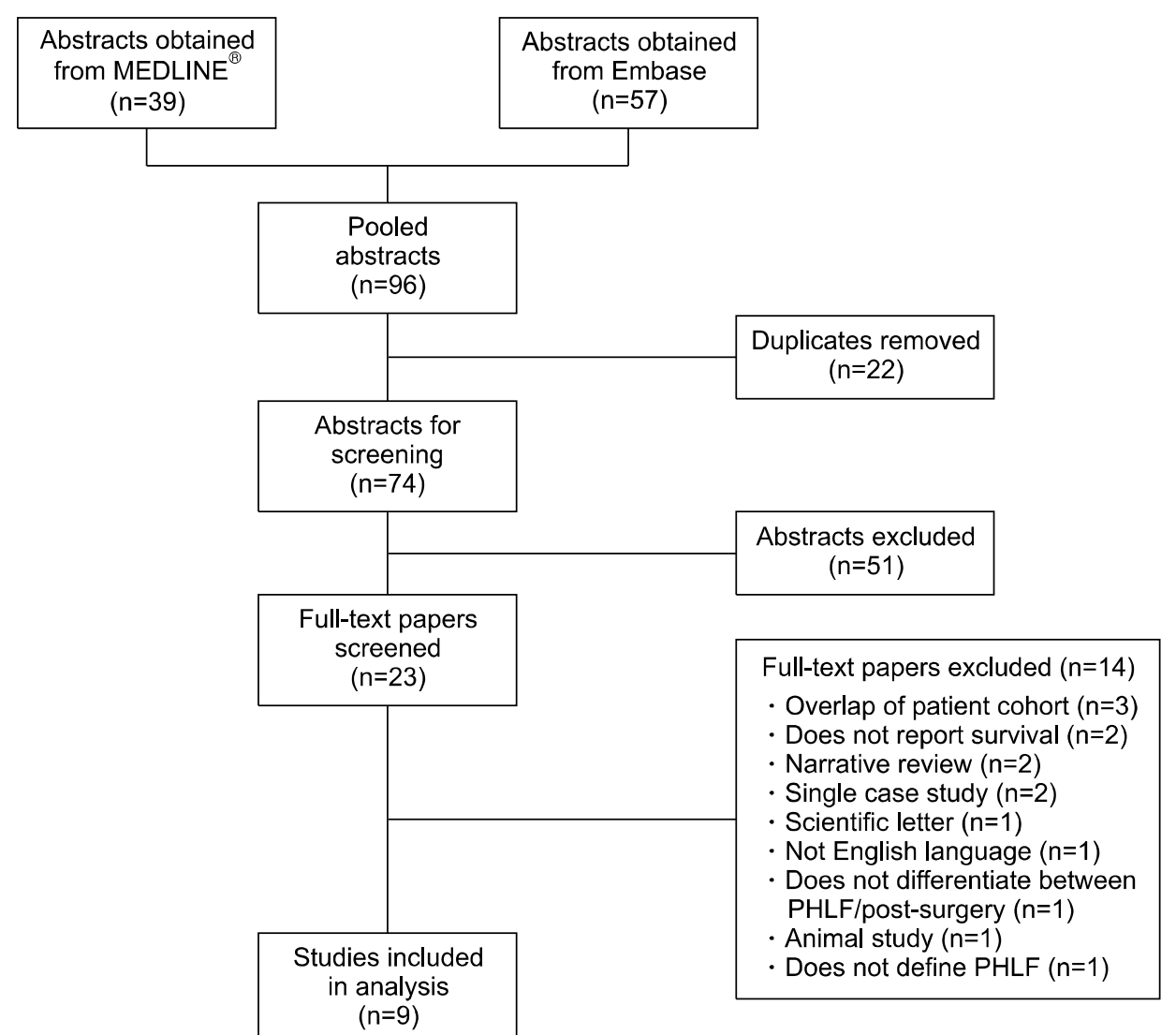

abstracts often provided little information on patient demographics and specific analysis. PHLF was rarely the main focus of the studies, with some of the authors only reporting this cohort as a subgroup. The definition of PHLF applied by the authors differed between the studies (Table 1). There were no uniform criteria that were reported for considering patients for LSS therapy.

\section{Patient characteristics}

The nine studies included a total of $\mathrm{N}=54$ patients (range: 2-13), of which $\mathrm{N}=34$ and $\mathrm{N}=20$ were from studies of MARS and PE, respectively. Further details of the study cohorts are reported in Table 2, although several studies did not report data for some of the relevant variables. Across the included studies, the majority of patients were male (25/33 reported patients) and were relatively young (median age among the reported studies: 54-69 years). A total of 26 patients underwent a major hepatectomy (right: 15; extended right: 9; left: 2). Partial hepatectomy was performed in 8 patients. 
Table 1. Reported criteria for PHLF diagnosis and to consider LSS

\begin{tabular}{|c|c|c|}
\hline Study & PHLF definition & Criteria to consider LSS \\
\hline \multicolumn{3}{|l|}{ MARS } \\
\hline Chiu et al. $(2006)^{18}$ & Liver failure within 4 weeks after operation & $\begin{array}{l}\text { Features of liver failure, including } \\
\text { hyperbilirubinemia of total bilirubin greater } \\
\text { than } 350 \mathrm{mmol} / \mathrm{L} \text {, or hepatic encephalopathy of } \\
\text { grade } 2 \text { or above. Patients with } \\
\text { PHLF were started considerably earlier, } \\
\text { given their rapid course of deterioration. } \\
\text { Patients with multiorgan failure in } \\
\text { which liver transplantation was not possible } \\
\text { were not considered for MARS }\end{array}$ \\
\hline Gilg et al. $(2018)^{19}$ & Balzan $(50: 50)$ criteria & $\begin{array}{l}\text { PHLF according to the Balzan (50:50) criteria } \\
\text { after major/extended hepatectomy } \\
\text { (removal of } 4 \text { Couinaud segments) }\end{array}$ \\
\hline Rusu et al. $(2009)^{20}$ & NR & $\begin{array}{l}\text { Rapidly progressive hepatic failure with } \\
\text { serum bilirubin level } \geq 10 \mathrm{mg} / \mathrm{dl} \\
\text { post-hepatectomy }\end{array}$ \\
\hline Saliba et al. $(2013)^{21}$ & Acute hepatic failure after major hepatectomy & NR \\
\hline $\begin{array}{l}\text { van de Kerkhove } \\
\text { et al. }(2003)^{22}\end{array}$ & $\begin{array}{l}\text { Liver failure following liver resection, } \\
\text { with an increasing } \\
\text { plasma bilirubin concentration }>250 \mu \mathrm{mol} / \mathrm{L}\end{array}$ & $\begin{array}{l}\text { PHLF following extensive partial liver resection } \\
\text { for liver or biliary malignancies' }\end{array}$ \\
\hline \multicolumn{3}{|l|}{ PE } \\
\hline $\begin{array}{l}\text { Asanuma } \\
\text { et al. }(2003)^{23}\end{array}$ & Postoperative liver failure due to hepatectomy & NR \\
\hline Lee et al. $(2017)^{24}$ & NR & $\begin{array}{l}\text { Hyperbilirubinemia }(>10 \mathrm{mg} / \mathrm{dl}) \text { with } \\
\text { early graft dysfunction }\end{array}$ \\
\hline $\begin{array}{l}\text { Usami et al. } \\
(1989)^{25}\end{array}$ & $\begin{array}{l}\text { Liver failure after hepatectomy= } \\
\text { 'Primary' liver dysfunction= } \\
\text { hepatic encephalopathy, increased serum Bili levels } \\
\text { to }>10 \mathrm{mg} / \mathrm{dl} / \text { intrahepatic cholestasis resistant } \\
\text { to drug therapy }\end{array}$ & $\begin{array}{l}\text { Hepatic encephalopathy, increased serum } \\
\text { Bilirubin to }>10 \mathrm{mg} / \mathrm{dl} \text { or intrahepatic } \\
\text { cholestasis resistant to drug therapy }\end{array}$ \\
\hline $\begin{array}{l}\text { Yonekawa et al. } \\
(2005)^{26}\end{array}$ & $\begin{array}{l}\text { Acute severe liver dysfunction, } \\
\text { with a total serum bilirubin level }>5 \mathrm{mg} / \mathrm{dl} \text { and } \\
\text { an ensuing grade } 2 \text { or higher coma that } \\
\text { developed within } 1 \text { month after surgery }\end{array}$ & NR \\
\hline
\end{tabular}

NR, not reported

\section{Treatment details}

Details on the number of cycles of treatment were available for all studies (Table 2). The mean number of treatment cycles ranged from 1.0 to 5.8 in the MARS studies and 5.0 to 28.5 for PE studies. The details on the type of dialyzate used were generally poorly reported and varied between studies.

\section{Mortality rates}

The 90-day mortality rates for the included studies are reported in Table 2. Saliba et al. ${ }^{21}$ reported a 6-month, rather than 90 -day mortality rate $(92 \%)$, and so was excluded from subsequent analysis. Pooling data from the remaining studies (Fig. 2), returned a 90-day mortality rate of $38 \%$ (95\% CI: 9-70\%). However, considerable het- erogeneity was detected, with an $\mathrm{I}^{2}$ statistic of $68 \%$ and this, along with the small sample size, resulted in the wide confidence interval. Subgroup analysis by the type of LSS returned pooled 90 -day mortality rates of $49 \%$ and $30 \%$ for MARS and PE, respectively.

\section{DISCUSSION}

Beyond supportive treatments for the loss of homeostasis that occurs during severe PHLF, treatment options are limited, exemplified by the lack of specific liver support technologies. Furthermore, the commonest indications for liver resection are primary and secondary liver cancer, precluding these patients from liver transplantation in the event of PHLF. The reported mortality for medically man- 
Table 2. Patient characteristics and treatment details

\begin{tabular}{|c|c|c|c|c|c|c|c|}
\hline Study & $\begin{array}{l}\text { Number } \\
\text { of } \\
\text { patients }\end{array}$ & $\begin{array}{l}\text { Age } \\
\text { (years) }\end{array}$ & $\begin{array}{l}\text { Gender } \\
(\% \text { male })\end{array}$ & Indication & $\begin{array}{l}\text { Number of } \\
\text { cycles }\end{array}$ & Dialysate & $\begin{array}{l}\text { 90-day } \\
\text { mortality }\end{array}$ \\
\hline \multicolumn{8}{|l|}{ MARS } \\
\hline Chiu et al. $(2006)^{18}$ & 4 & 64.0 & $4(100 \%)$ & $\begin{array}{r}\mathrm{HCC}^{-3}(75 \%) \\
\mathrm{CC}^{-1}(25 \%)\end{array}$ & $2.5 \pm 0.5$ & $\begin{array}{l}600 \mathrm{ml} \text { of } \\
20 \% \text { human albumin }\end{array}$ & $4(100 \%)$ \\
\hline Gilg et al. $(2018)^{19}$ & 10 & 69.5 & $6(60 \%)$ & $\begin{array}{rr}\text { HCC }-1 & (10 \%) \\
\mathrm{LM}^{-5} & (50 \%) \\
\mathrm{CC}-4 & (40 \%)\end{array}$ & $5.8 \pm 1.0$ & $\begin{array}{l}\text { Renal dialysis dose of } \\
35 \mathrm{ml} / \mathrm{kg} / \text { hour }\end{array}$ & $1(10 \%)$ \\
\hline Rusu et al. $(2009)^{20}$ & 2 & 54.0 & $1(50 \%)$ & $\begin{aligned} \mathrm{HCC}^{-1} & (50 \%) \\
\mathrm{LM}^{-1} & (50 \%)\end{aligned}$ & Mean $=1.0$ & $\begin{array}{l}\text { Dialysate with } \\
\text { a bicarbonate-based } \\
\text { buffer system }\end{array}$ & $0(0 \%)$ \\
\hline Saliba et al. $(2013)^{21}$ & 13 & NR & NR & NR & $3.5 \pm 1.9$ & NR & $92 \% *$ \\
\hline $\begin{array}{l}\text { van de Kerkhove } \\
\text { et al. }(2003)^{22}\end{array}$ & 5 & 60.0 & $4(80 \%)$ & $\begin{aligned} \mathrm{HCC}^{-1} & (20 \%) \\
\mathrm{LM}^{-3} & (60 \%) \\
\mathrm{CC}^{-1} & (20 \%)\end{aligned}$ & $5.2 \pm 2.5$ & NR & $4(80 \%)$ \\
\hline \multicolumn{8}{|l|}{ PE } \\
\hline $\begin{array}{l}\text { Asanuma } \\
\text { et al. }(2003)^{23}\end{array}$ & 2 & 65.0 & $2(100 \%)$ & $\begin{aligned} \mathrm{HCC}^{-1} & (50 \%) \\
\mathrm{LM}^{-1} & (50 \%)\end{aligned}$ & Mean $=9.0$ & $\begin{array}{l}5 \% \text { albumin solution plus } \\
\text { FFP or FFP alone }\end{array}$ & $0(0 \%)$ \\
\hline Lee et al. $(2017)^{24}$ & 3 & 67.0 & $2(67 \%)$ & $\begin{aligned} \mathrm{HCC}^{-1} & (33 \%) \\
\mathrm{CC}^{-}-2 & (67 \%)\end{aligned}$ & $5.3 \pm 2.5$ & FFP alone & $0(0 \%)$ \\
\hline Usami et al. $(1989)^{25}$ & 8 & 56.5 & NR & HCC-8 (100\%) & $28.5 \pm 38.6$ & NR & $5(63 \%)$ \\
\hline $\begin{array}{l}\text { Yonekawa } \\
\text { et al. }(2005)^{26}\end{array}$ & 7 & 63.0 & $6(86 \%)$ & $\begin{aligned} \text { HCC-4 } & (57 \%) \\
\mathrm{LM}^{-1} & (14 \%) \\
\text { PHCC-2 } & (29 \%)\end{aligned}$ & $5.0 \pm 4.0$ & $\begin{array}{l}5 \% \text { albumin solution plus } \\
\text { FFP or FFP alone }\end{array}$ & $3(43 \%)$ \\
\hline
\end{tabular}

Ages reported as medians, Numbers of cycles reported as mean $\pm \mathrm{SD}$, unless stated otherwise. Percentages are calculated manually, based on the numbers reported in the studies

* Six month mortality rate

FFP, fresh frozen plasma; HCC, hepatocellular carcinoma; LM, liver metastases; PHCC, perihilar cholangiocarcinoma; NR, not reported

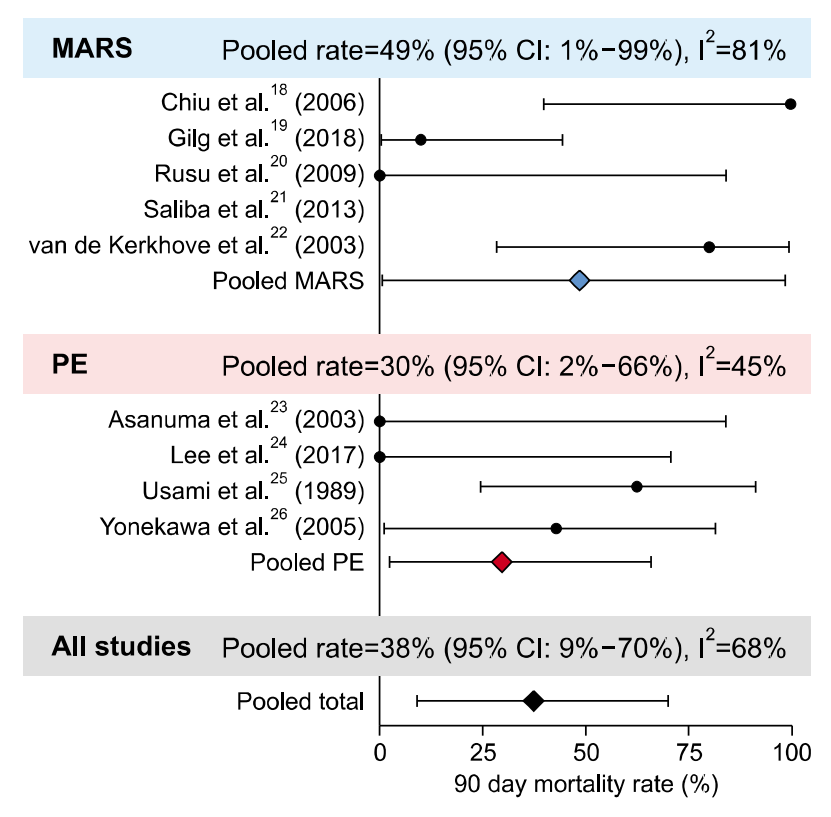

Fig. 2. Pooled analysis of 90-day mortality rates. aged severe PHLF is as high as $30-50 \%$. LSS, such as MARS and PE therapy, in theory, appear to be a bridging option while the remnant liver regenerates in volume and recovers its excretory and synthetic functions. Given the high mortality of medically managed severe PHLF, we undertook a systematic review of studies looking at PHLF outcomes after treatment with extracorporeal LSS.

Several factors, such as inadequate liver volume and/or liver function, sepsis, portal vein thrombosis, hepatic artery thrombosis, and small for portal flow syndromes can result in severe PHLF. Remnant liver function is more routinely assessed compared to remnant liver volume at most high volume centers, to identify patients at risk of PHLF pre-operatively. Sepsis, when encountered, is treated with broad-spectrum intravenous antibiotics and drainage of infected intra-abdominal collections. Patients with vascular insult are managed with interventional radiology or surgical options, where appropriate. In the absence of the above causes, a pathophysiology similar to that of 
SFSS or small for flow ${ }^{27,28}$ is believed to play a part. Increased blood flow through the available portal vessels causes increased pressure and an increased stress on the vascular endothelium. ${ }^{29}$ Such a pathological stress on the vessel wall leads to disruption of cellular processes in the liver instead of regeneration, driving hepatocyte apoptosis by stimulating Kupffer cells to hypersecrete prostaglandins and tumor necrosis factors, which further disrupt hepatic microcirculation.

In most patients developing PHLF, the underlying immunological changes are also considered contributory for the impaired hepatic regenerative properties. ${ }^{30}$ Epidermal Growth Factor, Transforming Growth Factor $\alpha$, and hepatocyte growth factor, Interleukin-6 (IL-6) are all shown to have a significant role in hepatic regeneration following hepatectomy and after acute liver injury. ${ }^{31-34}$ In contrast, cytokines are demonstrated to have a role in hepatic injury during sepsis and ischemia-reperfusion injury, ${ }^{30}$ and chronically elevated IL-6 levels are associated with inhibition of liver regeneration after injury. ${ }^{34}$ Overall, the role of growth factors and cytokines in the regulation of liver regeneration is multifaceted, and is less understood. Future well-planned trials with newer cytokine modulators such as Cytosorb may allow further investigation of the role of cytokines, and to assess if such systems have a role in the management of PHLF.

The common clinical manifestations of severe PHLF are: hyperbilirubinemia, metabolic acidosis and elevated lactate levels, raised ammonia levels, hepatic encephalopathy, and coagulopathy. LSS are used to manage these deranged clinical and biochemical parameters. MARS and $\mathrm{PE}$ can be used to temporarily replace some of the most crucial functions (detoxification, synthesis, heat regulation). ${ }^{35}$ These systems are able to remove hepatotoxins from the blood, a feat that cannot be fully achieved by simple hemofiltration or dialysis of the blood. ${ }^{36}$ This is since some of the hepatotoxins exist in protein-bound form and are lipophilic (e.g., bilirubin), and cannot be simply filtered out of the bloodstream. Moreover, traditional hemofiltration methods do not have selectivity for removal of toxic products.

However, we find here that the benefit of existing LSS seems modest, although use of these systems is not routine. PE and MARS have not been shown to significantly improve the mortality rates, but have helped im- prove some of the clinical outcomes in acute liver failure cases. $^{37,38}$ The pooled mortality rates from this review revealed an overall 90 -day mortality rate of $38 \%$. When split by LSS, MARS and PE were associated with mortality rates of $49 \%$ and $29 \%$, respectively. According to the Balzan definition, PHLF was associated with a mortality rate of $59 \%{ }^{39}$ The results of this review show promise, with the 90-day mortality rates by both modalities being less than those suggested by the Balzan criteria, which may suggest some benefit in the use of LSS as a treatment option for PHLF, however, with a caveat that the Balzan definition is not used for PHLF in all the studies. Similar results are reported by Gilg et al. ${ }^{40}$ in a review that evaluated only MARS as a treatment option for PHLF.

However, the current study has several limitations. The primary limitation was the small sample size of constituent studies, partly explained by the hesitation to offer the existing LSS options. This, coupled with the considerable heterogeneity in the mortality rates between studies, meant that the confidence intervals around the estimated mortality rates were very wide, approximately \pm 30 percentage points in terms of the overall pooled rate. We were also unable to adequately compare MARS and PE to each other, or to a control group that did not receive extra-corporeal liver support, to identify the relative benefits of these systems. Another potential cause of this wide confidence interval, and a limitation in itself, was the lack of a uniform PHLF definition, with all of the included studies using different criteria to define the condition. Such a limitation is unavoidable with the varying definitions that have evolved over the years. Despite these limitations, the current review assessed the quality and shortcomings of the current literature, and will help in identifying the areas for future research in the management of PHLF.

In conclusion, although there is currently insufficient evidence to recommend LSS for the routine treatment of PHLF patients, the lack of evidence highlights a considerable clinical knowledge gap, rather than proof that LSS should be disregarded in PHLF. We highlight that this gap is accompanied by a need for well-defined patient cohorts with PHLF to be considered for enrollment in to larger, multicenter, prospective studies to accurately evaluate the use of existing and newer LSS. Although our study found that MARS and PE systems had outcomes reported in 
PHLF, the roles of other systems, including bio-artificial systems and cytokine modulators (e.g. Cytosorb) may also warrant investigation in the context of PHLF.

\section{SUPPLEMENTARY DATA}

Supplementary data related to this article can be found at https://doi.org/10.14701/ahbps.2021.25.2.171.

\section{CONFLICT OF INTEREST}

The authors have no conflicts of interest to declare.

\section{SOURCE OF FUNDING}

None.

\section{ORCID}

Kamil Pufal: https://orcid.org/0000-0002-7596-3229

Alexander Lawson: https://orcid.org/0000-0001-5846-1756

James Hodson: https://orcid.org/0000-0003-3487-0090

Mansoor Bangash: https://orcid.org/0000-0001-5039-5184

Jaimin Patel: https://orcid.org/0000-0003-4120-3923

Chris Weston: https://orcid.org/0000-0002-9651-1264

Thomas van Gulik: https://orcid.org/0000-0003-3668-1381

Bobby VM Dasari: https://orcid.org/0000-0003-2375-1141

\section{AUTHOR CONTRIBUTIONS}

Conceptualization: BVMD. Data curation: KP, AL, BVMD. Formal analysis: KP, JH, MB, JP, BVMD. Methodology: KP, AL, JH, MB, JP, CW, BVMD. Project administration: JH, MB, JP, CW, TvG, BVMD. Visualisation: TvG, BVMD. Writing: Original draft: $\mathrm{KP}, \mathrm{JH}, \mathrm{CW}$, BVMD. Writing: review \&editing: $\mathrm{KP}, \mathrm{AL}, \mathrm{JH}, \mathrm{MB}, \mathrm{JP}$, CW, TvG, BVMD.

\section{REFERENCES}

1. Poon RT, Fan ST, Lo CM, Liu CL, Lam CM, Yuen WK, et al. Improving perioperative outcome expands the role of hepatectomy in management of benign and malignant hepatobiliary diseases: analysis of 1222 consecutive patients from a prospective database. Ann Surg 2004;240:698-708; discussion 708-710. 2. Zheng Y, Yang H, He L, Mao Y, Zhang H, Zhao H, et al.
Reassessment of different criteria for diagnosing post-hepatectomy liver failure: a single-center study of 1683 hepatectomy. Oncotarget 2017;8:89269-89277.

3. Andreatos N, Amini N, Gani F, Margonis GA, Sasaki K, Thompson VM, et al. Albumin-bilirubin score: predicting shortterm outcomes including bile leak and post-hepatectomy liver failure following hepatic resection. J Gastrointest Surg 2017;21: 238-248.

4. Schreckenbach T, Liese J, Bechstein WO, Moench C. Posthepatectomy liver failure. Dig Surg 2012;29:79-85.

5. Rahbari NN, Garden OJ, Padbury R, Brooke-Smith M, Crawford M, Adam R, et al. Posthepatectomy liver failure: a definition and grading by the International Study Group of Liver Surgery (ISGLS). Surgery 2011;149:713-724.

6. Gilg S, Sparrelid E, Isaksson B, Lundell L, Nowak G, Strömberg C. Mortality-related risk factors and long-term survival after 4460 liver resections in Sweden-a population-based study. Langenbecks Arch Surg 2017;402:105-113.

7. Farges O, Goutte N, Bendersky N, Falissard B; ACHBT-French Hepatectomy Study Group. Incidence and risks of liver resection: an all-inclusive French nationwide study. Ann Surg 2012;256:697704; discussion 704-705.

8. Mullen JT, Ribero D, Reddy SK, Donadon M, Zorzi D, Gautam $\mathrm{S}$, et al. Hepatic insufficiency and mortality in 1,059 noncirrhotic patients undergoing major hepatectomy. J Am Coll Surg 2007; 204:854-862; discussion 862-864.

9. Kantola T, Ilmakunnas M, Koivusalo AM, Isoniemi H. Bridging therapies and liver transplantation in acute liver failure, 10 years of MARS experience from Finland. Scand J Surg 2011;100:8-13.

10. Vaid A, Chweich H, Balk EM, Jaber BL. Molecular adsorbent recirculating system as artificial support therapy for liver failure: a meta-analysis. ASAIO J 2012;58:51-59.

11. van de Kerkhove MP, de Jong KP, Rijken AM, de Pont AC, van Gulik TM. MARS treatment in posthepatectomy liver failure. Liver Int 2003;23 Suppl 3:44-51.

12. Stange J, Ramlow W, Mitzner S, Schmidt R, Klinkmann H. Dialysis against a recycled albumin solution enables the removal of albumin-bound toxins. Artif Organs 1993;17:809-813.

13. Stange J, Mitzner SR, Risler T, Erley CM, Lauchart W, Goehl $\mathrm{H}$, et al. Molecular adsorbent recycling system (MARS): clinical results of a new membrane-based blood purification system for bioartificial liver support. Artif Organs 1999;23:319-330.

14. Larsen FS, Schmidt LE, Bernsmeier C, Rasmussen A, Isoniemi $\mathrm{H}$, Patel VC, et al. High-volume plasma exchange in patients with acute liver failure: an open randomised controlled trial. J Hepatol 2016;64:69-78.

15. European Association for the Study of the Liver. EASL clinical practical guidelines on the management of acute (fulminant) liver failure. J Hepatol 2017;66:1047-1081.

16. Richardson WS, Wilson MC, Nishikawa J, Hayward RS. The well-built clinical question: a key to evidence-based decisions. ACP J Club 1995;123:A12-A13.

17. Miller JJ. The inverse of the Freeman - Tukey double arcsine transformation. Am Stat 1978;32:138.

18. Chiu A, Chan LM, Fan ST. Molecular adsorbent recirculating system treatment for patients with liver failure: the Hong Kong experience. Liver Int 2006;26:695-702.

19. Gilg S, Sparrelid E, Saraste L, Nowak G, Wahlin S, Strömberg $\mathrm{C}$, et al. The molecular adsorbent recirculating system in posthepatectomy liver failure: results from a prospective phase I study. Hepatol Commun 2018;2:445-454.

20. Rusu EE, Voiculescu M, Zilisteanu DS, Ismail G. Molecular adsorbents recirculating system in patients with severe liver failure. Experience of a single Romanian centre. J Gastrointestin Liver 
Dis $2009 ; 18: 311-316$.

21. Saliba F, Camus C, Durand F, Mathurin P, Letierce A, Delafosse B, et al. Albumin dialysis with a noncell artificial liver support device in patients with acute liver failure: a randomized, controlled trial. Ann Intern Med 2013;159:522-531.

22. van de Kerkhove MP, de Jong KP, Rijken AM, de Pont AC, van Gulik TM. MARS treatment in posthepatectomy liver failure. Liver Int 2003;23 Suppl 3:44-51.

23. Asanuma Y, Sato T, Yasui O, Kurokawa T, Koyama K. Treatment for postoperative liver failure after major hepatectomy under hepatic total vascular exclusion. J Artif Organs 2003;6: $152-156$

24. Lee HJ, Shin KH, Song D, Lee SM, Chang CL, Chu CW, et al. Increasing use of therapeutic apheresis as a liver-saving modality. Transfus Apher Sci 2017;56:385-388.

25. Usami M, Ohyanagi H, Nishimatsu S, Kasahara H, Shiroiwa H, Ishimoto $\mathrm{S}$, et al. Therapeutic plasmapheresis for liver failure after hepatectomy. ASAIO Trans 1989;35:564-567.

26. Yonekawa C, Nakae H, Tajimi K, Asanuma Y. Effectiveness of combining plasma exchange and continuous hemodiafiltration in patients with postoperative liver failure. Artif Organs 2005;29:324328.

27. Golriz M, Majlesara A, El Sakka S, Ashrafi M, Arwin J, Fard $\mathrm{N}$, et al. Small for size and flow (SFSF) syndrome: an alternative description for posthepatectomy liver failure. Clin Res Hepatol Gastroenterol 2016;40:267-275.

28. Eipel C, Abshagen K, Vollmar B. Regulation of hepatic blood flow: the hepatic arterial buffer response revisited. World $\mathrm{J}$ Gastroenterol 2010;16:6046-6057.

29. Allard MA, Adam R, Bucur PO, Termos S, Cunha AS, Bismuth $\mathrm{H}$, et al. Posthepatectomy portal vein pressure predicts liver failure and mortality after major liver resection on noncirrhotic liver. Ann Surg 2013;258:822-829; discussion 829-830.

30. Fan M, Wang $\mathrm{X}, \mathrm{Xu} \mathrm{G}$, Yan Q, Huang W. Bile acid signaling and liver regeneration. Biochim Biophys Acta 2015;1849:196-200.

31. Simpson KJ, Lukacs NW, Colletti L, Strieter RM, Kunkel SL.
Cytokines and the liver. J Hepatol 1997;27:1120-1132.

32. Cressman DE, Greenbaum LE, DeAngelis RA, Ciliberto G, Furth $\mathrm{EE}$, Poli V, et al. Liver failure and defective hepatocyte regeneration in interleukin-6-deficient mice. Science 1996;274:13791383.

33. Dello SA, Bloemen JG, van de Poll MC, van Dam RM, Stoot $\mathrm{JH}$, van den Broek MA, et al. Gut and liver handling of interleukin-6 during liver resection in man. HPB (Oxford) 2011;13: 324-331.

34. Blindenbacher A, Wang X, Langer I, Savino R, Terracciano L, Heim MH. Interleukin 6 is important for survival after partial hepatectomy in mice. Hepatology 2003;38:674-682.

35. Donati G, La Manna G, Cianciolo G, Grandinetti V, Carretta E, Cappuccilli M, et al. Extracorporeal detoxification for hepatic failure using molecular adsorbent recirculating system: depurative efficiency and clinical results in a long-term follow-up. Artif Organs 2014;38:125-134.

36. Dominik A, Stange J, Pfensig C, Borufka L, Weiss-Reining H, Eggert M. Reduction of elevated cytokine levels in acute/acuteon-chronic liver failure using super-large pore albumin dialysis treatment: an in vitro study. Ther Apher Dial 2014;18:347-352.

37. Roth GA, Faybik P, Hetz H, Ankersmit HJ, Hoetzenecker K, Bacher A, et al. MCP-1 and MIP3-alpha serum levels in acute liver failure and molecular adsorbent recirculating system (MARS) treatment: a pilot study. Scand J Gastroenterol 2009;44:745-751.

38. Stutchfield BM, Simpson K, Wigmore SJ. Systematic review and meta-analysis of survival following extracorporeal liver support. Br J Surg 2011;98:623-631.

39. Balzan S, Belghiti J, Farges O, Ogata S, Sauvanet A, Delefosse $\mathrm{D}$, et al. The "50-50 criteria" on postoperative day 5: an accurate predictor of liver failure and death after hepatectomy. Ann Surg 2005;242:824-828, discussion 828-829.

40. Sparrelid E, Gilg S, van Gulik TM. Systematic review of MARS treatment in post-hepatectomy liver failure. HPB (Oxford) 2020; 22:950-960. 